\title{
HIGH SENSITIVE C-REACTIVE PROTEIN AS AN INDICATOR FOR PRO-INFLAMMATORY STATUS IN DIFFERENT DEGREES OF MAJOR DEPRESSION
}

\author{
Sujata Bhattacharya1, Ushasi Banerjee ${ }^{2}$, Suparna Roy ${ }^{3}$, Asish Mukhopadhyay ${ }^{4}$ Indranil Chakraborty5, Anindya Dasgupta ${ }^{6}$ \\ ${ }^{1}$ Medical Officer, Barasat District Hospital, 24 PGS (N), West Bengal. \\ ${ }^{2}$ Assistant Professor, Department of Biochemistry, North Bengal Medical College, Darjeeling, West Bengal, India. \\ ${ }^{3}$ Assistant Professor, Department of Biochemistry, Calcutta National Medical College, Kolkata, West Bengal, India. \\ 4 Professor, Department of Psychiatry, Calcutta National Medical College, Kolkata, West Bengal, India. \\ 5 Professor, Department of Biochemistry, College of Medicine and Sagore Dutta Hospital, Kamarhati, Kolkata. \\ ${ }^{6}$ Professor, Department of Biochemistry, Calcutta National Medical College, Kolkata, West Bengal, India.
}

ABSTRACT
BACKGROUND
Studies indicate that along with many other factors, low grade inflammation may play an important contributory role in the
development of major depressive psychosis. This may add up as a confounding factor for different complications related to this major
psychological disorder. The role of hsCRP as a marker of low grade inflammation has been explored and analysed in the present
study.

\section{METHODS}

HsCRP, Total Cholesterol (TC), Triglyceride (TG) and Fasting Blood Glucose (FBG) were measured in 49 cases of major depression against 40 age and body weight (BMI) matched control subjects. The degree of depression in the case group was assessed by the HAM-D score. Data were analysed for any differences in these parameters between the case and control groups followed by correlation and regression analysis to assess the strength of association between the study parameters and the predictive values of serum cholesterol, triglyceride, FBG and HAM-D score on hsCRP.

\section{RESULTS}

HsCRP, TC and TG were significantly higher in the case group. The correlation and regression analyses revealed that hsCRP was strongly associated $(\mathrm{r}=0.559, \mathrm{P}<0.001)$ and dependent (beta $=0.579, \mathrm{P}<0.001$ ) on the HAM-D score only.

\section{CONCLUSION}

These results not only indicate a definite association of low grade inflammation with major depressive psychosis, but also suggest a close linear relationship between this low grade inflammation and the degree of depression. The researchers propose that hsCRP is a good indicator for monitoring the pro-inflammatory status and the degree of severity of the disease process in major depressive psychosis.

\section{KEYWORDS}

HAM-D Score, hsCRP, Low Grade Inflammation, Major Depressive Psychosis.

HOW TO CITE THIS ARTICLE: Bhattacharya S, Banerjee U, Roy S, et al. High sensitive C-reactive protein as an indicator for proinflammatory status in different degrees of major depression. J. Evolution Med. Dent. Sci. 2016;5(44):2731-2735, DOI: $10.14260 /$ jemds/2016/638

\begin{abstract}
INTRODUCTION
In terms of its prevalence and sufferings, depression is a disorder of major public health importance along with the huge economic burden for the individual and the society overall. In India, prevalence of depression in community varies from 1.7 to 7.4 per thousand population.[1] Pathogenesis of depression is not fully understood, but studies suggest that among many other precipitating factors low grade systemic inflammation plays an important contributory role in the development of depression. [2] A few studies have suggested that depression may be associated with increased production of pro-inflammatory cytokines such as IL-1, IL-6 and interferon.
\end{abstract}

Financial or Other, Competing Interest: None.

Submission 16-04-2016, Peer Review 11-05-2016,

Acceptance 17-05-2016, Published 01-06-2016.

Corresponding Author:

Dr. Anindya Dasgupta,

Professor \& HOD,

Department of Biochemistry,

Calcutta National Medical College,

Kolkata-700014, West Bengal, India.

E-mail: anindya653@gmail.com

DOI: $10.14260 /$ jemds $/ 2016 / 638$
C-Reactive Protein (CRP) is a commonly used marker of inflammatory diseases, when used to study the role of low grade inflammation in the future risk for disease development. [3] Elevated CRP levels have been associated with psychological distress and depression.[4-6] Depression may result in elevated CRP level, an inflammatory state may cause depression or both the depression and elevated CRP level may be due to another unmeasured disease process. Data from several large United States and European cohorts indicate that distribution of circulating high-sensitive CRP (hsCRP) level appears comparable among men and women with $50^{\text {th }}$ percentile for gender being about $1.5 \mathrm{mg} / \mathrm{dL}$.[6,7]

A large cross-sectional population studies with 5000-7000 participants reported an association between CRP levels and depression.[6-8] However, in another study this association disappeared when estimates were adjusted for confounding factors, such as chronic illness and body mass index. Similar observations were corroborated in other studies as well.[7,9]

\section{OBJECTIVES}

Conflicts exist whether there is any association between the major depression and CRP level. We hypothesized that a low grade inflammation might exist in the pathogenesis of 
depression. Accordingly, the present study was designed to assess any possible association of hsCRP level that measures the low grade inflammation with major depression in our study population.

\section{MATERIALS AND METHODS}

The study was conducted in the Department of Psychiatry and Department of Biochemistry of a Tertiary Care Medical College and Hospital of Eastern India during the period of one year from January 2013 to January 2014.

Newly diagnosed patients of depression were included in the study following inclusion and exclusion criteria as mentioned below.

\section{Inclusion Criteria}

a) All cases of newly diagnosed major depressive disorder.

b) Patients of either sex.

c) Age limit between 15-55 years.

d) Patients who are willing to enrol in the study and who had given written informed consent.

\section{Exclusion Criteria for the Case Group were the Following}

a) Patients who were on any other medication that affects hsCRP level (e.g. anti-inflammatory drugs, tobacco, oral contraceptives, etc.)

b) Patients with any infection (e.g. Bacterial/viral/fungal/mycobacterial).

c) Patients with any allergic complication of infection, such as rheumatic fever.

d) Patients with any inflammatory disease such as rheumatoid arthritis, juvenile chronic arthritis, ankylosing spondylitis, psoriatic arthritis, systemic vasculitis, polymyalgia rheumatica, Reiter's disease, Crohn's disease, familial Mediterranean fever, etc.

e) Patients with myocardial infarction, tumour embolisation, acute pancreatitis.

f) Patients with trauma due to surgery, burns, fracture.

g) Patients with malignancies such as lymphoma, carcinoma, etc.

h) Pregnant women.

\section{Experimental Protocol}

Informed written consents were obtained from the participants. The study protocol strictly adhered to the Helsinki Declaration 1975 revised in 2000 for human studies and was approved by the Institutional Ethics Committee.

Thereafter, the investigators selected fifty (50) patients fulfilling selection criteria among newly diagnosed depressed patients attending Psychiatry OPD on convenience basis in the case group.

Patients suffering from depression were screened with 'Mini International Neuropsychiatric Interview (MINI).[10] and confirmed with DSM-IV-TR. Hamilton Rating Scale for Depression (HRSD/HAM-D).[11] was used for assessing depression. Forty (40) apparently healthy age and sex matched individuals were enrolled as control subjects in the study.

Venous blood from patients and individuals from control group were collected as per prefixed aseptic protocol after 12 hours of fasting. Plasma fasting glucose (FBG), serum cholesterol and serum triglyceride were measured by standard spectrophotometric procedures in the autoanalyser (XL-600 from ERBA, Transasia, Mumbai, India). Serum hsCRP was assayed by immunoturbidimetric assay kit (ERBA, Mumbai, India). All procedures were checked for precision by assessing the Coefficient of Variation (CV) of the concerned analytical methods.

\section{STATISTICAL ANALYSIS}

The data were analysed for assessing the significance of differences between the mean values of hsCRP and lipid parameters between the case and control groups with the help of both parametric student $t$ test and non-parametric MannWhitney test. Any possible dependence of the hsCRP on the confounding factors was assessed by multiple regression analysis. All statistical analyses were performed by using SPSS software version 17 for Windows.

\section{RESULTS}

Data obtained were first analysed for the matching between case and control groups (Results not shown in Tables). There was no significant difference in the mean age of case group (32.24 \pm 11.00 years) and control group $(33.73 \pm 9.07$ years), $\mathrm{P}=0.77$. Body weights $(\mathrm{Kg})$ of case and control groups $(52.96 \pm 7.51$ and $53.25 \pm 6.9$ respectively, $P>0.05)$ and the sex distribution ( 34 vs 25 males and 16 vs 15 females in the case and control groups respectively, $(\chi 2=0.298, \mathrm{P}=0.58)$ revealed that selected case and control subjects were properly matched for body weight and gender.

Further analysis of the data showed that although the FBG concentration showed no significant difference between the case and control groups, serum hsCRP, serum triglyceride and serum cholesterol levels exhibited significant difference between these two groups as evident from both ' $\mathrm{t}$ ' test and Mann-Whitney U test (Table 1 and Table 2).

\begin{tabular}{|c|c|c|c|c|c|c|}
\hline \multirow[t]{2}{*}{ Parameters } & \multirow{2}{*}{$\begin{array}{c}\text { Cases } \\
(n=50) \\
\text { Mean } \pm \text { SD }\end{array}$} & \multirow{2}{*}{$\begin{array}{c}\text { Controls } \\
(n=40) \\
\text { Mean } \pm \text { SD }\end{array}$} & \multicolumn{2}{|c|}{$\begin{array}{c}\text { Standard Error } \\
\text { Mean }\end{array}$} & \multirow[t]{2}{*}{$\begin{array}{c}\mathrm{t} \\
\text { value }\end{array}$} & \multirow{2}{*}{$\begin{array}{c}\text { P value } \\
\text { (Level of } \\
\text { Significance) }\end{array}$} \\
\hline & & & Cases & Controls & & \\
\hline Serum hsCRP (mg/dL) & $2.03 \pm 0.93$ & $0.84 \pm 0.49$ & 0.13 & 0.07 & 7.21 & $\mathrm{P}=<0.001^{*}$ \\
\hline $\begin{array}{c}\text { Serum Total Cholesterol } \\
(\mathrm{mg} / \mathrm{dL})\end{array}$ & $174.34 \pm 38.32$ & $153.02 \pm 27.82$ & 5.47 & 4.39 & 2.94 & $\mathrm{P}=0.004^{*}$ \\
\hline Serum Triglyceride $(\mathrm{mg} / \mathrm{dL})$ & $140.93 \pm 76.51$ & $99.30 \pm 34.28$ & 10.93 & 5.42 & 3.18 & $\mathrm{P}=0.002^{*}$ \\
\hline Plasma FBG (mg/dL) & $103.32 \pm 38.18$ & $93.30 \pm 12.26$ & 5.45 & 1.93 & 1.59 & $\mathrm{P}=0.115$ \\
\hline
\end{tabular}

Level of sig. P $<0.05$ at $95 \%$ CI. *P value significant at 0.05 level. 


\begin{tabular}{|c|c|c|c|c|c|c|}
\hline Parameters & $\begin{array}{c}\text { Cases } \\
(\mathbf{n = 5 0} \\
\text { Median }\end{array}$ & $\begin{array}{c}\text { Controls } \\
(\mathbf{n = 4 0 )} \\
\text { Median }\end{array}$ & $\begin{array}{c}\text { Mann- } \\
\text { Whitney } \\
\mathbf{U}\end{array}$ & $\begin{array}{c}\text { Wilcoxon } \\
\mathbf{W}\end{array}$ & $\begin{array}{c}\mathbf{Z} \\
\text { value }\end{array}$ & $\begin{array}{c}\text { Asymp. Sig. } \\
\text { (2-tailed) }\end{array}$ \\
\hline $\begin{array}{c}\text { Serum hsCRP } \\
\text { (mg/dL) }\end{array}$ & 1.71 & 0.87 & 174.5 & 994.5 & -6.644 & $\mathrm{P}<0.001^{*}$ \\
\hline $\begin{array}{c}\text { Serum Total } \\
\text { Cholesterol } \\
\text { (mg/dL) }\end{array}$ & 170.0 & 154.5 & 652.5 & 1472.5 & -2.704 & $\mathrm{P}=0.007^{*}$ \\
\hline $\begin{array}{c}\text { Serum } \\
\text { Triglyceride } \\
\text { (mg/dL) }\end{array}$ & 122 & 100 & 603.5 & 1423.5 & -3.107 & $\mathrm{P}=0.002^{*}$ \\
\hline $\begin{array}{c}\text { Plasma FBG } \\
\text { (mg/dL) }\end{array}$ & 96.2 & 90.4 & 750 & 1570. & -1.898 & $\mathrm{P}=0.058$ \\
\hline
\end{tabular}

Table 2: Nonparametric Test: Mann-Whitney U Test for Significance Between Different Study Parameters

Level of sig. $\mathrm{P}<0.05$ at $95 \% \mathrm{CI}$.

*P-value significant at 0.05 level.

Bivariate Pearson's correlation study, however, suggested a strong association between the hsCRP and degree of depression only (Table 3, Figure 1 ).

$\mathrm{X}_{1}=$ HAMD score, $\mathrm{X}_{2}=$ Serum hsCRP $(\mathrm{mg} / \mathrm{dL}), \mathrm{X}_{3}=$ Serum Total Cholesterol (mg/dL), $X_{4}=$ Serum triglyceride (mg/dL), $X_{5}$ = Plasma FBG $(\mathrm{mg} / \mathrm{dL})$

\begin{tabular}{|c|c|c|}
\hline Parameters & $\begin{array}{c}\text { Pearson's } \\
\text { Correlation } \\
\text { Coefficient: } \mathbf{r}\end{array}$ & $\begin{array}{c}\text { Level of } \\
\text { Significance }\end{array}$ \\
\hline $\mathrm{r}_{12}$ & 0.559 & $\mathrm{P}<0.001^{*}$ \\
\hline $\mathrm{r}_{13}$ & 0.031 & $\mathrm{P}=0.831$ \\
\hline $\mathrm{r}_{14}$ & 0.024 & $\mathrm{P}=0.868$ \\
\hline $\mathrm{r}_{15}$ & 0.174 & $\mathrm{P}=0.233$ \\
\hline
\end{tabular}

Table 3: Bivariate Correlation Analysis among Different Parameters in the Case Group $(n=50)$

Level of sig. $\mathrm{P}<0.05$ at $95 \% \mathrm{CI} * \mathrm{P}$-value significant at 0.05 level.

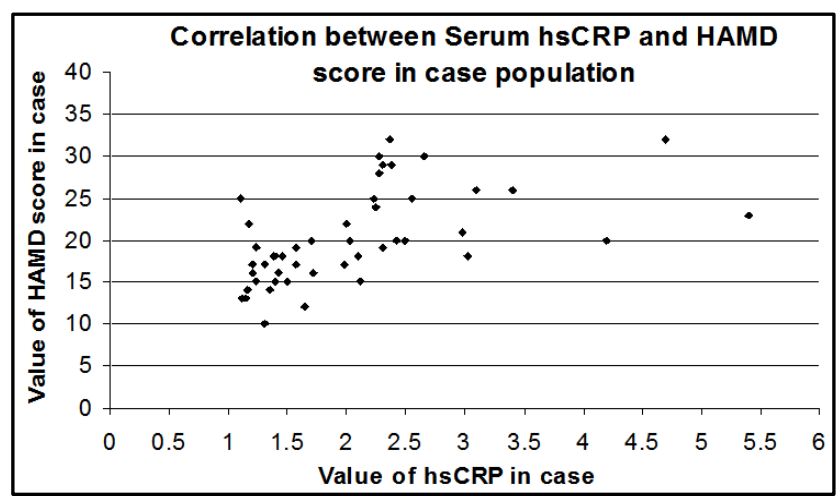

Fig. 1: Scatter Plot showing Positive Bivariate Correlation ( $r=0.559 ; P<0.05)$ between Serum hsCRP $(\mathrm{mg} / \mathrm{dL})$ and HAMD Score in the Case Subjects ( $N=50)$

Based on this finding, multiple linear regression was performed considering hsCRP as the only dependent variable and serum cholesterol, serum triglyceride, FBG and HAM-D score as independent variables taken together. It was found that hsCRP had significant dependence only on the HAM-D score $(\beta=0.735, t=6.286$. $P<0.001)$ (Table 4$)$.

\begin{tabular}{|c|c|c|c|c|c|c|}
\hline & \multirow{2}{*}{ Model } & \multicolumn{2}{|c|}{\begin{tabular}{|c|}
$\begin{array}{c}\text { Unstandardized } \\
\text { Coefficients }\end{array}$ \\
\end{tabular}} & \multirow{2}{*}{$\begin{array}{c}\begin{array}{c}\text { Standardized } \\
\text { Coefficients }\end{array} \\
\text { Beta }\end{array}$} & \multirow{2}{*}{$\mathbf{t}$} & \multirow{2}{*}{ Sig. } \\
\hline & & B & $\begin{array}{l}\text { Std. } \\
\text { Error }\end{array}$ & & & \\
\hline \multirow{5}{*}{1} & (Constant) & 1.024 & 0.625 & & 1.640 & $\mathrm{P}=1.08$ \\
\hline & FBG & $2.16 \mathrm{E}-03$ & 0.002 & 0.123 & 1.06 & $\mathrm{P}=0.295$ \\
\hline & $\begin{array}{c}\text { Serum } \\
\text { Cholesterol } \\
\text { (mg/dL) }\end{array}$ & $-5.68 E-03$ & 0.003 & -0.233 & -1.913 & $\mathrm{P}=0.062$ \\
\hline & \begin{tabular}{|c|} 
Serum \\
Triglyceride \\
(mg/dL) \\
\end{tabular} & $-1.13 E-03$ & 0.001 & -0.092 & -0.762 & $\mathrm{P}=0.450$ \\
\hline & HAM-D Score & $9.847 \mathrm{E}-02$ & 0.019 & 0.579 & 5.070 & $\mathrm{P}=<0.001^{*}$ \\
\hline \multicolumn{7}{|c|}{ aDependent Variable: hsCRP } \\
\hline
\end{tabular}

Level of sig. $\mathrm{P}<0.05$ at $95 \% \mathrm{CI}$.

*P-value significant at 0.05 level.

Precision of the tests was monitored assessing the coefficient of variation (CV). CV for the FBG, serum cholesterol and triglyceride remained under 9 percent, while that for the hsCRP was below 6 percent on average throughout the study period.

\section{DISCUSSION}

For nearly two decades, it has been recognized that immune system plays a major role in depression. Role of systemic immune activation has been documented in major depression with respect to changes in acute phase response, notably enhancement of positive and diminution of negative acute phase proteins that mark the systemic inflammation. ${ }^{[3-9]}$ CRP is an acute phase protein that suggests the systemic inflammation. This study, however, stems from the research question whether systemic inflammation precedes the onset of depressive symptoms or occurs as a part of somatic manifestation of the depressive phenotype. Although the CRP level is traditionally only elevated in severe inflammation, newer assays with improved sensitivity are able to measure hsCRP in apparently healthy individuals, permitting an exploration of the postulated association between subclinical systemic inflammation and risk of depression.

Inferential statistical calculation considering both parametric and non-parametric distribution of data in the present study showed that serum hsCRP level was significantly higher in newly diagnosed depressive cases than those of healthy controls (Table 1 and 2). In a recent study it was reported that elevated CRP levels were associated with an increased risk of psychological distress and depression. This association was observed in 73131 individuals in a cross sectional analyses and in prospective analyses for hospitalization with depression.[12] Although previous studies have corroborated the association of elevated CRP levels with psychological distress and depression, the results were conflicting and varied according to differential distribution of race, region or gender.[4,7,8] A significant positive association between the Centre for Epidemiologic Studies Depression Scale (CES-D) and hsCRP levels among African-American men with depression was found that was absent in their female counterparts.[13] However, no such gender based variations 
regarding the association of hsCRP with depression was observed in the present study.

Some earlier studies have shown the probable mechanism of CRP rise in depression. Depression might promote an inflammatory response by activating immune response. ${ }^{[14]} \mathrm{A}$ higher transcription of both Chemokine Ligands (CCL24) as well as Chemokine Receptors (CCR6) have been reported recently in major depressive disorders.[15] These chemokines are found to attract increasing numbers of $\mathrm{T}$ cells and eosinophils.[16,17], whereas their receptors potentiate the immunological functions of macrophages, $\mathrm{B}$ cells and helper $\mathrm{T}$ cells.[18] Alternatively, the effects of depression on inflammation might be due to its link to psychological stress. For a long time, depressive illness is known to be associated with an increase in several phases of psychological stress as evident by various biochemical tests including the cortisol response test to psychological stressors.[19-22] The latter has also been associated with excessive production of interleukin6 (IL-6). IL-6 is also the main pro-inflammatory cytokine inducing the synthesis of Type I acute phase protein such as CRP. Also psychological stress has been shown to increase oxidative stress, which in turn through modified lipids and lipoproteins is thought to initiate an inflammatory response in arterial wall. ${ }^{[8,9]}$ It is recognized that depressive symptoms are associated with enhanced stress-induced norepinephrine responses and norepinephrine dysregulation. [23] Preliminary evidence suggests that nor-epinephrine dependent adrenergic stimulation results in activation of nuclear factor $\kappa \beta$ (NF- $\kappa \beta)$, a transcription factor known to promote IL-6 gene expression.[24] Severity of the depressive symptoms, anger and hostility, alone and in combination is associated with increased gene expression of pro-inflammatory cytokines and chemokines.[25-27] and elevated levels of IL-6.[28] Thus, individuals who show elevated levels of stress may respond to daily life stressors with excessive stress induced sympathetic activation that triggers an NF- $\kappa \beta$-dependent cascade of proinflammatory events that contribute to increase in hsCRP. [29,30]

\section{CONCLUSION}

Thus, the present study strongly suggests that the depressive illness is closely linked to a pro-inflammatory condition and therefore heralds an early onset of all such related complications like premature atherosclerosis, cardiovascular disorders and cerebrovascular accidents.

\section{RECOMMENDATION}

The present study, hence, suggests a close monitoring and surveillance of all depressive patients for pro-inflammatory markers, particularly the hsCRP to enable an early intervention for preventing low grade inflammation related disorders and atherosclerotic diseases in these patients.

\section{REFERENCES}

1. Grover S, Dutt A, Avasthi A. An overview of Indian research in depression. Indian journal of psychiatry 2010;52(1):S178-88.

2. Miller $\mathrm{AH}$, Maletic $\mathrm{V}$, Raison CL. Inflammation and its discontents: the role of cytokines in the pathophysiology of major depression. Biological psychiatry 2009;65(9):732-41.
3. Gimeno D, Kivimaki M, Brunner EJ, et al. Associations of Creactive protein and interleukin-6 with cognitive symptoms of depression: 12-year follow-up of the whitehall II study. Psychological medicine 2009;39(3):413-23.

4. Puustinen PJ, Koponen $\mathrm{H}$, Kautiainen $\mathrm{H}$, et al. Psychological distress and C-reactive protein: do health behaviours and pathophysiological factors modify the association? European archives of psychiatry and clinical neuroscience 2011;261(4):277-84.

5. Tiemeier H, Hofman A, Van Tuijl HR, et al. Inflammatory proteins and depression in the elderly. Epidemiology 2003;14(1):103-7.

6. Danner M, Kasl SV, Abramson JL, et al. Association between depression and elevated C-reactive protein. Psychosomatic medicine 2003;65(3):347-56.

7. Almeida OP, Norman P, Hankey GJ, et al. The association between C-reactive protein concentration and depression in later life is due to poor physical health: results from the health in men study (HIMS). Psychological medicine 2007;37(12):1775-86.

8. Douglas KM, Taylor AJ, O'Malley PG. Relationship between depression and C-reactive protein in a screening population. Psychosomatic medicine 2004;66(5):679-83.

9. Miller GE, Stetler CA, Carney RM, et al. Clinical depression and inflammatory risk markers for coronary heart disease. The American journal of cardiology 2002;90(12):1279-83.

10. Sheehan DV, Lecrubier $Y$, Sheehan $K H$, et al. The miniinternational neuropsychiatric interview (MINI): the development and validation of a structured diagnostic psychiatric interview for DSM-IV and ICD-10. The Journal of clinical psychiatry 1998;59(20):22-33;quiz 4-57.

11. Hamilton M. A rating scale for depression. Journal of neurology, neurosurgery, and psychiatry 1960;23:56-62.

12. Wium-Andersen MK, Orsted DD, Nielsen SF, et al. Elevated C-reactive protein levels, psychological distress, and depression in 73, 131 individuals. JAMA psychiatry 2013;70(2):176-84.

13. Cooper DC, Trivedi RB, Nelson KM, et al. Sex differences in associations of depressive symptoms with cardiovascular risk factors and metabolic syndrome among African Americans. Cardiovascular psychiatry and neurology 2013;2013:979185.

14. Yudkin JS, Kumari M, Humphries SE, et al. Inflammation, obesity, stress and coronary heart disease: is interleukin6 the link? Atherosclerosis 2000;148(2):209-14.

15. Powell TR, McGuffin P, D'Souza UM, et al. Putative transcriptomic biomarkers in the inflammatory cytokine pathway differentiate major depressive disorder patients from control subjects and bipolar disorder patients. PloS one 2014;9(3):e91076.

16. Patel VP, Kreider BL, Li Y, et al. Molecular and functional characterization of two novel human $\mathrm{C}-\mathrm{C}$ chemokines as inhibitors of two distinct classes of myeloid progenitors. The Journal of experimental medicine 1997;185(7):116372.

17. White JR, Imburgia C, Dul E, et al. Cloning and functional characterization of a novel human CC chemokine that binds to the CCR3 receptor and activates human eosinophils. Journal of leukocyte biology 1997;62(5):66775. 
18. Ai LS, Lee SF, Chen SS, et al. Molecular characterization of CCR6: involvement of multiple domains in ligand binding and receptor signaling. Journal of biomedical science 2004;11(6):818-28.

19. Daley SE, Hammen C, Rao U. Predictors of first onset and recurrence of major depression in young women during the 5 years following high school graduation. Journal of abnormal psychology 2000;109(3):525-33.

20. Kendler KS, Karkowski LM, Prescott CA. Causal relationship between stressful life events and the onset of major depression. The American journal of psychiatry 1999;156(6):837-41.

21. Lewinsohn PM, Allen NB, Seeley JR, et al. First onset versus recurrence of depression: differential processes of psychosocial risk. Journal of abnormal psychology 1999;108(3):483-9.

22. Burke HM, Davis MC, Otte C, et al. Depression and cortisol responses to psychological stress: a meta-analysis. Psychoneuroendocrinology 2005;30(9):846-56.

23. Kang DH, McCarthy DO. The effect of psychological stress on neutrophil superoxide release. Research in nursing \& health 1994;17(5):363-70.

24. Ressler KJ, Nemeroff CB. Role of serotonergic and noradrenergic systems in the pathophysiology of depression and anxiety disorders. Depression and anxiety 2000;12(1):2-19.

25. Suarez EC. Joint effect of hostility and severity of depressive symptoms on plasma interleukin-6 concentration. Psychosomatic medicine 2003;65(4):5237.
26. Suarez EC, Lewis JG, Kuhn C. The relation of aggression, hostility, and anger to lipopolysaccharide-stimulated tumor necrosis factor (TNF)-alpha by blood monocytes from normal men. Brain, behavior, and immunity 2002;16(6):675-84.

27. Suarez EC, Lewis JG, Krishnan RR, et al. Enhanced expression of cytokines and chemokines by blood monocytes to in vitro lipopolysaccharide stimulation are associated with hostility and severity of depressive symptoms in healthy women. Psychoneuroendocrinology 2004;29(9):1119-28.

28. Yu B, Becnel J, Zerfaoui $M$, et al. Serotonin 5hydroxytryptamine $(2 \mathrm{~A})$ receptor activation suppresses tumor necrosis factor-alpha-induced inflammation with extraordinary potency. The Journal of pharmacology and experimental therapeutics 2008;327(2):316-23.

29. Suarez EC, Krishnan RR, Lewis JG. The relation of severity of depressive symptoms to monocyte-associated proinflammatory cytokines and chemokines in apparently healthy men. Psychosomatic medicine 2003;65(3):362-8.

30. Rothermundt $M$, Arolt $V$, Peters $M$, et al. Inflammatory markers in major depression and melancholia. Journal of affective disorders 2001;63(1-3):93-102. 